\title{
REMOVAL OF COPPER(II) FROM SUGAR-CANE SPIRITS EMPLOYING CHITOSAN
}

Bruno C. Janegitz, Andrea Oliveira, Marcos S. Gomes, Elen R. Sartori, Edenir R. Pereira-Filho e Orlando Fatibello-Filho* Departamento de Química, Centro de Ciências Exatas e de Tecnologia, Universidade Federal de São Carlos, CP 676, 13560-970 São Carlos - SP, Brasil

Recebido em 14/1/09; aceito em 8/7/09; publicado na web em 11/1/10

\begin{abstract}
REMOVAL OF COPPER(II) FROM SUGAR-CANE SPIRITS EMPLOYING CHITOSAN. A method employing chitosan as complexant agent in the removal of copper(II) ions generally present in the Brazilian cachaça samples is herein proposed. The efficiency of this method is attributed to its high capacity of metal cations adsorption, mainly due to presence of hydroxyl and amine groups that can serve as chelating sites. The removal of copper(II) ions from this alcoholic beverage was efficient employing either in column and batch system. The analysis were carried out employing the flame atomic absorption spectrometry and the remaining copper(II) concentrations in the treated cachaça were lower than LOD of FAAS technique.
\end{abstract}

Keywords: cachaça; alcoholic beverages; chitosan.

\section{INTRODUCTION}

The Brazilian production of sugar-cane spirits called as cachaça, a tipically Brazilian alcoholic beverage made from fermentation and distillation of sugar-cane juice is estimated to be 1.6 billion of liters per year, ${ }^{1,2}$ showing a great social and economical importance. Moreover, Brazil is the biggest producer of sugar-cane spirit all over the world followed by India and Cuba. ${ }^{3,4}$ However, somewhat more than $1 \%$ of the volume produced in Brazil is exported and efforts have been made to increase the export volume and/or qualify of the cachaça as an international Brazilian beverage. ${ }^{5}$ Great improvements have been made regarding to the knowledge of cachaça's chemical composition in the past decade. Consequently, quality control has been improved, and producers are now more successful at controlling its chemical composition and sensory profile..$^{6-9}$

Other substances are present in the process of cachaça's manufacturing besides alcohol and water, leading to the product with color, flavor and aroma characteristics. The Brazilian Ministry of Agriculture ${ }^{10}$ established many quality criteria for this product (Official Union Diary, Jun/29/2005, Normative Instruction $N^{\circ} 13$ ). Thus, between these important criteria established ones is related to the maximum copper concentration, which is not allowed to be higher than $5 \mathrm{mg} \mathrm{L}^{-1}$. Copper has been historically used to make the pot stills for sugar-cane spirits, especially craft sugar-cane spirits. It is certain that during the distillation process, a compound commonly a basic copper carbonate, $\left[\mathrm{CuCO}_{3} \mathrm{Cu}(\mathrm{OH})_{2}\right]$ is formed on the still walls. This substance can be dissolved by acidic alcoholic vapors and the product, the cachaça, may be contaminated. ${ }^{11}$

Moreover, copper is an essential element in the human diet; however intake large quantities can be toxic. For example, copper accumulation in the liver can leading to the Wilson's disease, which leads to neurological and psychiatric disturbs, ${ }^{12}$ and it is well known that adverse effect of copper is the catalytic formation of ethyl carbamate, a potentially carcinogenic substance, being the one main technical obstacles for the exportation of the Brazilian sugar-cane spirits. ${ }^{13}$ In some spirituous beverages made by producers in the Brazil, generally homemade or "artisanal cachaças", the copper levels found may be above the maximum allowed limit and

\footnotetext{
*e-mail: bello@ufscar.br
}

frequently double distillation is often required to reduce this element content. ${ }^{14}$ An usual and practice procedure that can be employed to reduce the copper level in the cachaça is a simple washing of condenser walls with a solution containing water and lemon juice or a solution of citric acid, in the concentration of $5 \% \mathrm{v} / \mathrm{v}$ lemon juice:water. ${ }^{15}$ Unfortunately, most of producers, mainly the small manufacturers do not clean condenser walls, and, in several samples a copper concentration of $20 \mathrm{mg} \mathrm{L}^{-1}$ was found. ${ }^{15}$

There are some studies about removing copper ions from beverages based on the formation of insoluble chelating agents ${ }^{16}$ and the use of chelating resins. ${ }^{17}$ Lima et al.,${ }^{18}$ employed activated carbon to remove copper(II) ions from sugar-cane spirits, however depending on the amount of carbon used, it can also remove other substances present in this beverage. In this case, the chemical profile and the organoleptic properties of the treated cachaça with activated carbon can change, affecting thus its quality. Neves et $a l .,{ }^{19}$ developed an efficient method for removal copper ions from alcoholic beverages employing for this purpose, calcium or magnesium carbonates, obtaining the copper residual contents less than $1 \mathrm{mg} \mathrm{L}^{-1}$. However, in this case, studies have been conducted related to the quality and the sensory profile of cachaça samples treated by this procedure.

Chitosan (Figure 1) is a linear $\beta$-1,4-linked polysaccharide (similar to cellulose) that is obtained by the partial deacetylation of chitin, a major component of the shells of crustaceans such as crab, shrimp, and crawfish. Because chitin deacetylation is incomplete, chitosan is formally a copolymer composed of glucosamine and $\mathrm{N}$-acetylglucosamine. ${ }^{20}$ Chitosan (CTS) has been reported for the high potentials of adsorption metal ions, ${ }^{21-24}$ due to the presence of hydroxyl and amine groups that can serve as chelating sites. There are many works reported in the literature that use chitosan in the adsorption of copper(II). Vieira et al. studied adsorption and desorption of binary mixtures of copper(II) and mercury(II) ions on natural and crosslinked chitosan membranes. ${ }^{25}$ Boddu et al. studied the removal of copper(II) and nickel(II) ions from aqueous solutions by a composite chitosan biosorbent. ${ }^{26}$ Chen et al. investigated the comparative adsorption of $\mathrm{Cu}$ (II), $\mathrm{Zn}$ (II), and $\mathrm{Pb}$ (II) ions in aqueous solution on the crosslinked chitosan with epichlorohydrin..$^{27}$ Thus, taking into account the higher complexant capacity of the chitosan, in this paper, a method for removal of copper(II) ions from sugar-cane spirits employing chitosan is proposed. 


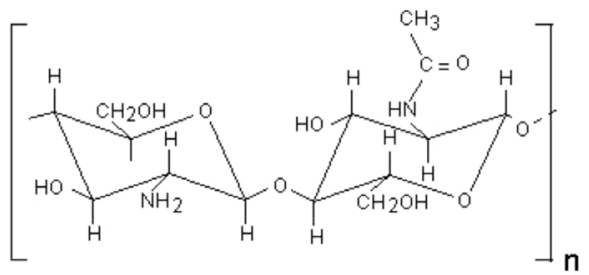

Figure 1. Molecular structure of chitosan

\section{EXPERIMENTAL}

\section{Reagents, samples, and solutions}

All solutions were prepared using analytical grade reagents and Millipore (Bedford, MA, USA) Milli-Q water from a Millipore MilliQ system with a resistivity not less than $18 \mathrm{M} \Omega \mathrm{cm}$. All glassware and polypropylene flasks were washed with neutron detergent, soaked in $10 \%$ v/v nitric acid (Merck, Darmstadt, Germany) and rinsed with Milli-Q water prior to use.

For copper determination by flame atomic absorption spectrometry (FAAS), the standard additions method (SAM), was adopted for correcting transport interference effects, by the presence of different amounts of ethanol in the analyzed samples. In fact, in the studies conducted by Rocha et al., ${ }^{28}$ it was verified that the physical properties of alcoholic solutions (especially viscosity and surface tension) can change the analytical signal in FAAS, interfering on the nebulization process. However, these effects can be corrected using the SAM, for all solutions prepared in this same medium presenting in this case, the same physical properties.

A $1000 \mathrm{mg} \mathrm{L}^{-1}$ copper(II) stock solution was used to prepare an intermediate standard solution containing $100 \mathrm{mg} \mathrm{L}^{-1}$ copper(II) by appropriate dilution with distilled and Milli-Q water, and then increasing amounts of this solution were added to identical aliquots of each sample. A SAM plot was built with exact matrix matching between samples and standards. Sugar cane spirits were purchased in local supermarkets and the method for copper removal was applied without any previous treatment of the sample.

The chitosan (Aldrich) employed in this work, was previous characterized by $\mathrm{RMN}{ }^{1} \mathrm{H}$ and conductmetric titration ${ }^{29}$ presenting a deacetylation degree of $82 \%$.

\section{Procedures for copper(II) removal}

\section{Column procedure}

Aliquots of $20.0 \mathrm{~mL}$ of solution $(40 \% \mathrm{v} / \mathrm{v}$ ethanol) containing $30.0 \mathrm{mg} \mathrm{L}^{-1}$ copper(II) were percoled in a column of $7 \mathrm{~cm}$ of length and $0.8 \mathrm{~cm}$ of diameter filled up with $2.5 \mathrm{~g}$ of chitosan. The residual concentration of copper(II) were determined by FAAS.

\section{Batch system procedure}

For a volume of $25.0 \mathrm{~mL}$ of cachaça (40\% v/v ethanol), a mass of about $200 \mathrm{mg}$ of chitosan was added. The chitosan amount was the same as used by Janegitz et al..$^{29}$ where the chitosan/copper ratio has been optimized in aqueous solution. The samples were stirred for $10 \mathrm{~min}$ and after the complete sedimentation of the solid phase, aliquots of $5 \mathrm{~mL}$ of treated cachaça were taken and made up to $10.0 \mathrm{~mL}$ with Milli-Q water and the residual concentration of copper(II) were determined by FAAS.

\section{Instrumentation}

Experiments with flame atomic absorption spectrometry (FAAS) were performed using a Varian Spectra AA640 (Australian) spectrometer equipped with a deuterium lamp for background correction. The equipment was operated in according to the recommendations of the manufacturer for maximum sensitivity using an air-acetylene flame. The measurements were performed at $327 \mathrm{~nm}$, using a copper hollow cathode lamp.

\section{RESULTS AND DISCUSSION}

The concentration of chitosan employed was previously investigated in order to remove efficiently copper(II) ions present in this aqueous ethanol medium and aqueous medium only. The investigation of sorption of copper(II) ions in aqueous medium was based in the work conducted by Janegitz et al..$^{29}$ In this way, can compare the complexant/ adsorption capacity of this biopolymer in the removal of copper(II) ions in aqueous medium proceeded in this work, as soon as, in the study previously reported by Janegitz et al., as observed in the Figure 2.

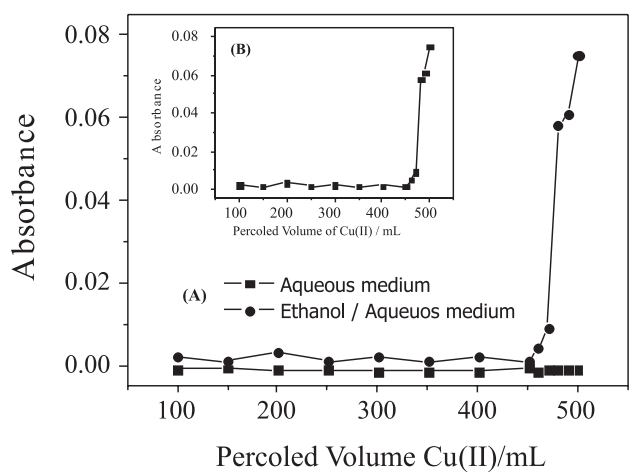

Figure 2. Removal of copper(II) ions from solutions containing $635 \mathrm{mg} \mathrm{L}^{-1}$ of copper(II) in aqueous/ethanol (A e B) medium and aqueous medium (A), in a column containing about $2.5 \mathrm{~g}$ of chitosan

The capacity of chitosan to remove copper(II) from aqueousethanol solution was verified employing the same experimental conditions as those determined by Janegitz et al. ${ }^{29}$ by using a $635 \mathrm{mg} \mathrm{L}^{-1}$ copper(II) solution and a column containing $2.5 \mathrm{~g}$ of chitosan. In fact, can be observed that in aqueous ethanol medium there was an enhancement in the removal of copper(II) ions present in this solvent as can be observed in this figure. It can be observed that the relation chitosan/ copper(II) in this medium was $0.152 \mathrm{mg}$ of copper(II) $/ \mathrm{mg}$ of chitosan.

Chitosan possesses distinct chemical and biological properties. In its linear polyglucosamine chains of high molar mass, chitosan has reactive amino and hydroxyl groups, amenable to chemical reaction. Additionally, amino groups make chitosan a cationic polyelectrolyte ( $\mathrm{pKa} \cong 6.5$ ). This basicity gives chitosan singular properties; chitosan is soluble in aqueous acidic media at $\mathrm{pH}$ lower than 6.5 and when dissolved possesses high positive charge on $-\mathrm{NH}_{3}$ groups (Figure 1). ${ }^{30}$

In this work the conditional $\mathrm{pH}$ of the samples was verified before and after the treatment with chitosan, observing no change in these values of cachaça samples (in both cases, before and after, the $\mathrm{pH}$ kept close to 6 , and the chitosan was maintained as started form (powder), because its lower solubility in $40 \% \mathrm{v} / \mathrm{v}$ ethanol medium).

There are various low-cost adsorbents for heavy metal removal from water. Instead of using commercial activated carbon, researchers have worked on inexpensive materials, such as chitosan, zeolites, and other adsorbents, which have high adsorption capacity by ionexchange properties, complexation ${ }^{31}$ or simple adsorption..$^{32}$

Various mechanisms seem to be appropriate to the description of the effective removal of metal ions (in this case copper(II)) using chitosan, because of presence of primary amino groups and hydroxyl groups..$^{33,34}$

The particle size can also interfere in the adsorption capacity by chitosan. ${ }^{35,36}$ Such increase in particle size of chitosan, of course, decreases surface area available for adsorption, resulting in lower 
adsorption, fact related with the contact surface, between chitosan and metal ion. In this work the particle size of chitosan used was 50 mesh in agreement with the literature, ${ }^{33}$ a good size of particle when use the chitosan as metal ion adsorbent.

Aqueous ethanol solutions (40\% v/v ethanol) containing about 10 $\mathrm{mg} \mathrm{L}^{-1}$ of copper(II) ions were treated by the proposed column procedure.

The quantification of copper(II) residual content in the liquid phase was carried out by FAAS, indicating that copper(II) concentration was lower than the detection limit (LOD) of equipment in all cachaça samples treated by chitosan, as verified in the Table 1 .

Table 1. Determination of copper(II) concentration $\left(\mathrm{mg} \mathrm{L}^{-1}\right)$ in sugar-cane spirits by FAAS before and after treatment with chitosan

\begin{tabular}{lccc}
\hline Sample & $\begin{array}{c}\text { [copper(II)] } \\
\text { untreated sample }\end{array}$ & $\begin{array}{c}\text { [copper(II)] } \\
\text { after treatment } \\
\text { (column procedure) }\end{array}$ & $\begin{array}{c}\text { [copper(II)] } \\
\text { after treatment } \\
\text { (batch system) }\end{array}$ \\
\hline A & 4.05 & $<0.03$ & $<0.03$ \\
B & 6.56 & $<0.03$ & $<0.03$ \\
C & 12.6 & $<0.03$ & $<0.03$ \\
D & 4.70 & $<0.03$ & $<0.03$ \\
\hline
\end{tabular}

The efficiency of removal of copper(II) ions from sugar-cane spirits is due to the great ability of this biopolymer linking the metal cations. This efficiency of removal is improved by adsorption phenomenon of the metal on the solid phase of chitosan. The chitosan was performed in the batch system procedure and observed that the removal of copper(II) ions present in the cachaça samples was effective and the results are showed in the Table 1. Through the results obtained, it can be observe that this method presented similar results to the column procedure.

Following this experiment, the treated samples were centrifuged and filtered, removing the solid phase, chitosan, from the liquid phase (aqueous ethanol medium). It is important to point out that after fifteen days, treated cachaça samples by the proposed method have not settle and/or suspended chitosan or any particles for samples studied in the temperature ranged form 4 to $25^{\circ} \mathrm{C}$. In fact, cachaça is a strongly flavored beverage and its dominant taste/aroma seems to mask any minor changes in its composition. However, taking into account these important and concern factors, experiments must be conducted in order to assembly the sensorial qualities of treated cachaça. In the moment the following experiments with the treated cachaça by proposed methods (with carbonates ${ }^{19}$ and chitosan) will be carried out together with a manufacturer of alcoholic beverage that is interesting in those technologies.

\section{CONCLUSIONS}

The removal of copper(II) ions present in the cachaça samples employing chitosan was efficient in both the column system and the batch system, due to the higher capacity of adsorption of this biopolymer. The conditional $\mathrm{pH}$ of samples was not altered after the treatment with this biopolymer. Smaller amounts of chitosan can be use for removal of copper(II) because the biopolymer present a high adsorbent capacity for copper (II) ions. Thus, it may plausibly be affirmed that the chitosan can be used in the treatment of copper(II) removal of cachaça samples.

\section{ACKNOWLEDGMENTS}

The authors are grateful to Fundação de Amparo à Pesquisa do Estado de São Paulo (FAPESP) (Proc. 06/05146-0), Conselho Nacional de Desenvolvimento Científico e Tecnológico (CNPq) and Coordenação de Aperfeiçoamento de Pessoal de Nível Superior (CAPES) for financial support.

\section{REFERENCES}

1. Isique, D. W.; Cardello, H. M. A. B.; Faria, J. B.; Cienc. Tecnol. Aliment. 1998, $18,356$.

2. Drinks International; Major export drive for world's "biggest Brand" 1994, 401.

3. Cardello, H. M. A. B.; Faria, J. B.; Cienc. Tecnol. Aliment. 1998, 18, 169.

4. Barros, G. A.; Ribeiro, J. C. M.; Rolim, A. A. B.; Belo Horizonte INDI. 1999, (INDI/SAI/001/VP-11/01/89), 32.

5. Brasil, Decreto Federal No 4.072, Jan 3/1/2002, Art. 91.

6. Boscolo, M.; Bezerra, C. W. B.; Cardoso, D. R.; Lima-Neto, B. S.; Franco, D. W.; J. Braz. Chem. Soc. 2000, 11, 86.

7. Capote, T.; Marcó, L. M.; Alvarado, J.; Greaves, E. D.; Spectr. Acta Part B 1999, 54, 1463.

8. Cunha e Silva, R. M.; Almeida, E.; Valencia, E. P. E.; Nascimento-Filho, V. F.; J. Radioanal. Nucl. Chem. 2004, 206, 3.

9. Bettin, S. M.; Isique, W. D.; Franco, D. W.; Eur. Food Res. Tech. 2002, 215, 169.

10. Brasil, Ministério da Agricultura, Diário Oficial da União, Instrução Normativa $\mathrm{N}^{\circ} 13$, de 29/6/2005.

11. Lima-Neto, B. S.; Bezerra, C. W. D.; Polastro, L. R.; Campos, P.; Nascimento, R. F.; Furuya, S. M. B.; Franco, D. W.; Quim. Nova 1994, 17, 220.

12. Sing, K.; Mehtab, S.; Jain, A. K.; Anal. Chim. Acta 2006, 575, 25.

13. Bruno, S. N. F.; Vaitsman, D. S.; Kunigami, C. N.; Brasil, M. G.; Food Chem. 2007, 104, 1345.

14. Bizzeli, L. C.; Ribeiro, C. A. F.; Novaes, F. V.; Sci. Agricol. 2000, 57,100 .

15. Cardoso, M. G.; Produção artesanal de aguardentes, Ed. da UFLA: Lavras, 2000.

16. Wucherpfenning, K.; Deustche Lebensmittel-Rundschau. 1992a, 88, 313.

17. Wucherpfenning, K.; Deustche Lebensmittel-Rundschau. 1992b, 88, 344.

18. Lima, A. J. B.; Cardoso, M. G.; Guerreiro, M. C.; Pimentel, F. A.; Quim. Nova 2006, 29, 247.

19. Neves, E. A.; Oliveira, A.; Fernandes, A. P.; Nóbrega, J. A.; Food Chem. 2007, 101, 33 .

20. Varma, A. J.; Deshpande, S. V.; Kennedy, J. F.; Carbohydr. Pol. 2004, 55,77

21. Juang, R. S.; Shao, H. J.; Water Res. 2002, 36, 2999.

22. Wu, F. C.; Tseng, R. L.; Juang, R. S.; J. Hazard. Mater. 2000, 73, 63.

23. Vasconcelos, H. L.; Camargo, T. P.; Gonçalvez, N. S.; Neves, A.; Laranjeira, M. C. M.; Fávere, V. T.; React. Funct. Polym. 2008, 68, 572.

24. Evans, J. R.; Davids, W. G.; MacRae, J. D.; Amirbahman, A.; Water Res. 2002, 36, 219.

25. Vieira, R. S.; Guibal, E.; Silva, E. A.; Beppu, M. M.; Adsorption 2007, 13,603 .

26. Boddu, V. M.; Abburi, K.; Randolph, A. J.; Smith, E. D.; Sep. Sci. Technol. 2008, 43, 1365.

27. Chen, A. H.; Liu, S. C.; Chen, C. Y.; Chen, C. Y.; J. Hazard. Mater. 2008, 154, 184.

28. Rocha, F. R. P.; Nóbrega, J. A.; J. Chem. Educ. 1996, 73, 982.

29. Janegitz, B. C.; Lourenção, B. C.; Lupetti, K. O.; Fatibello-Filho, O.; Quim. Nova 2007, 30, 879.

30. Yi, H.; Wu, L. Q.; Bentley W. E.; Ghodssi, R.; Rubloff, G. W.; Culver, J. N.; Payne G. F.; Biomacromol. 2005, 6, 2881.

31. Deans, J. R.; Dixon, B. G.; Water Res. 1992, 26, 469.

32. Couphlin, R. W.; Deshaies, M. R.; Davis, E. M.; Enuiron. Prog. 1990, 9, 35.

33. Inoue, K.; Yoshizuka, K.; Ohto, K.; Anal. Chim. Acta 1999, 388, 209.

34. Ni, C.; Xu, Y.; J. Appl. Polym. Sci. 1996, 59, 499.

35. Huang, C. P.; Chung, Y. C.; Liou, M. R.; J. Hazard. Mater. 1996, 45, 265.

36. Ngah, W. S. W.; Isa, I. M.; J. Appl. Polym. Sci. 1998, 67, 1067. 